05

\title{
Магнитные термопары на основе пермаллоев Co-Fe и $\mathrm{Ni}-\mathrm{Fe}$
}

\author{
(C) Т.М. Панахов, ${ }^{1}$ А.А. Исаева, ${ }^{1}$ Н.М. Рафииев, ${ }^{1}$ А.Г. Гусейнов ${ }^{2,9}$ \\ ${ }^{1}$ Азербайджанский университет архитектуры и строительства, \\ AZ1073 Баку, Азербайджан \\ ${ }^{2}$ Бакинский государственный университет, \\ AZ1148 Баку, Азербайджан \\ ๑ e-mail: aguseinov@bsu.edu.az
}

Поступило в Редакцию 28 ноября 2018 г.

В окончательной редакции 25 января 2019 г.

Принято к публикации 12 февраля 2019 г.

Полученные на двухвалковой литейной установке сплавы $\mathrm{Co}-\mathrm{Fe}$ и $\mathrm{Ni}-\mathrm{Fe}$ в виде гибкой тонкой пленки с аморфной структурой в обычном и намагниченном состояниях являются подходящими материалами для изготовления магнитных термопар. Тонкопленочная форма ветвей термопары в переменном магнитном поле позволяет минимизировать погрешности в измерениях температуры, вызываемые нагревом за счет индукционных токов.

DOI: $10.21883 / J T F .2019 .07 .47797 .410-18$

\section{Введение}

Пермаллои, являющиеся сплавами триады железа, обладают широким спектром физико-химических свойств, представляют практический интерес и широко применяются в разных отраслях промышленности [1-3]. Особые магнитные свойства, жаростойкость, высокая коррозионная стойкость, малый коэффициент термического расширения позволяют применять их в условиях высокого уровня радиоактивности, температуры и при наличии контактов с другими материалами. Магнитомягкие сплавы $\mathrm{Co}-\mathrm{Fe}$, легированные разными элементами, обладают высоким значением магнитной проницаемости и применяются в виде пленочного материала при изготовлении высокочастотных трансформаторов [4].

Получение пленочных сплавов $\mathrm{Co}-\mathrm{Fe}$ и $\mathrm{Ni}-\mathrm{Fe}$ в виде гибкой тонкой пленки с аморфной структурой в обычном и намагниченном состояниях позволяет расширять область их практического применения. В частности, можно изготовить на их основе магнитные термопары, способные контактировать с ферромагнитными телами непосредственно. В настоящей работе приводятся результаты изготовления и исследования термоэлектрических свойств термопары из сплавов $\mathrm{Co}-\mathrm{Fe}$ и $\mathrm{Ni}-\mathrm{Fe}$, имеющие форму узкой тонкой пленки с аморфной структурой.

Одним из самых простых сенсоров для измерения и регистрации температуры является термопара. Термопары надежно работают в большинстве сред, выдерживая экстремальные температуры, вибрацию и даже ионизирующее излучение. Термопары в лабораторных условиях и в промышленности часто подвергаются воздействию посторонних, обычно нежелательных и неконтролируемых магнитных полей. При этом параметры сенсоров на основе проволочных металлических пар несколько искажаются под действием магнитного поля. В настоящей работе нами изготовлены термопары из пленочных пермаллоев.

\section{Изготовление термопары и методика измерений}

Для получения магнитомягких лент сплавов $\mathrm{Co}-\mathrm{Fe}$ и $\mathrm{Ni}-\mathrm{Fe}$ использована двухвалковая литейная установка. Расплавленный в тигле металлический сплав путем донного слива подавался в виде падающей струи расплава в зазор между двумя охлаждающими валками. Валки охлаждались струей потока паров жидкого азота. Процесс охлаждения ленты до температуры $300-400^{\circ} \mathrm{C}$ происходил в среде смеси азота и инертных газов. Толщина ленты варьировала между 100 и $200 \mu \mathrm{m}$, а ширина составила $3 \mathrm{~cm}$. На рис. 1 представлено АФМ изображение поверхности ленты Co-Fe (50\% - Со и $50 \%$ - Fe). Как видно из рисунка, структура ленты однородная и ее поверхность достаточно гладкая. Рентгеноструктурный анализ показал, что ленты обладают аморфной структурой. При отжиге ленты на воздухе при температуре $900^{\circ} \mathrm{C}$ степень шероховатости намного уменьшается. Как было показано в работе [5], прирост массы происходит за счет окисления пленки. Неравномерность прироста, видимо, связана с незначительной ликвацией Со [6] и наличием небольшого градиента концентрации железа в исследованной области.

Из полученной ленты были вырезаны полоски шириной $1.5 \mathrm{~mm}$ и длиной от 20 до $25 \mathrm{~cm}$. Концы $\mathrm{Ni}-\mathrm{Fe}$ полоски были сплавлены и сварены полосками $\mathrm{Co}-\mathrm{Fe}$ методом электросварки в дистиллированной воде. На рис. 2 показано SEM-изображения полученного контакта двух сплавов. Ровные линии и черты фигуры шестигранника свидетельствует о том, что в процессе образования контакта сплав $\mathrm{Co}-\mathrm{Fe}$ кристаллизуется.

Один из спаев дифференциальной термопары находился при $0^{\circ} \mathrm{C}$, а другой спай в термостате, где была возможность получить температуры от -196 до $500^{\circ} \mathrm{C}$. ТермоЭДС измерялась компенсационным методом. 

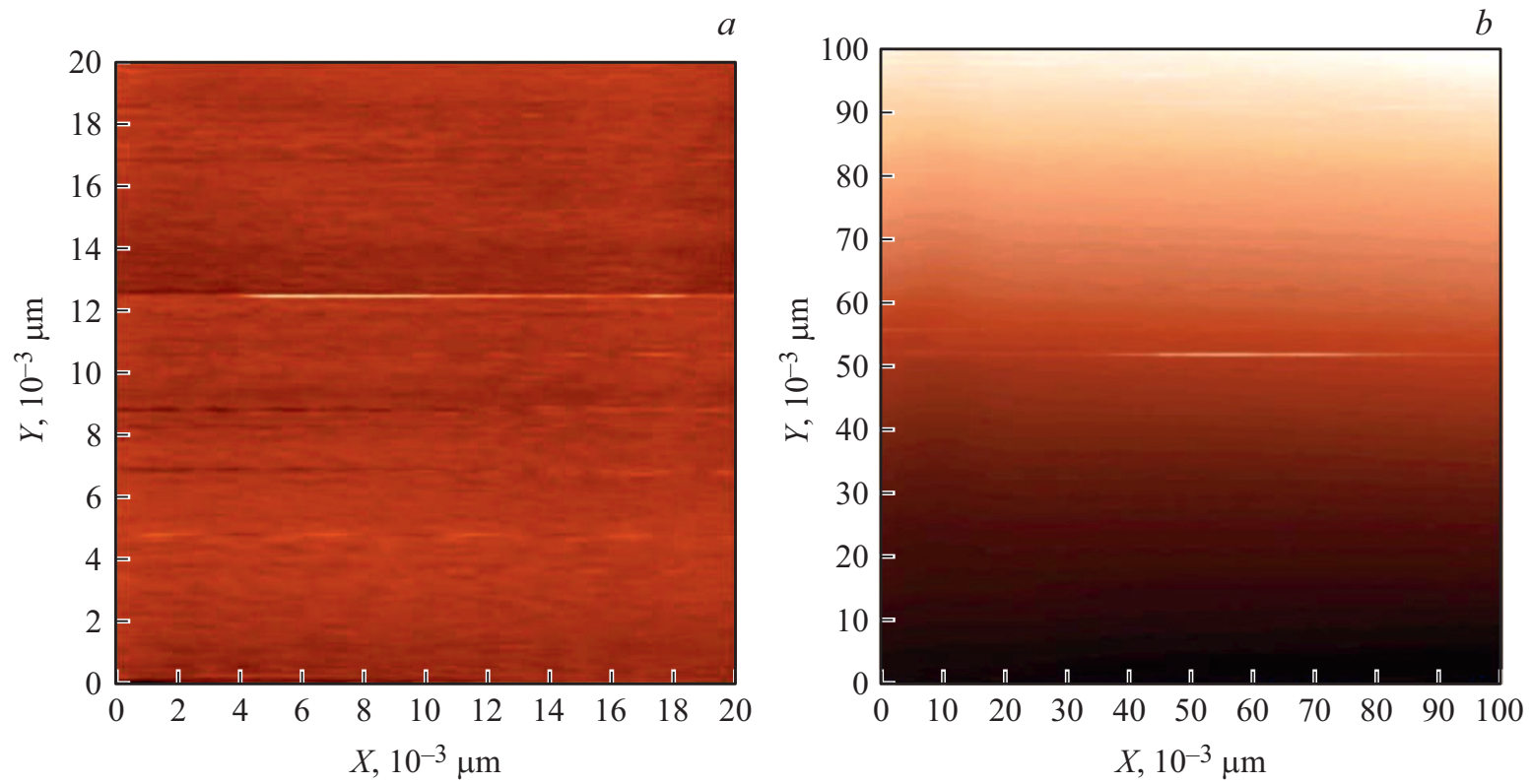

Рис. 1. АФМ-изображения поверхности ленты $\mathrm{Co}-\mathrm{Fe}(50 \%-\mathrm{Co}$ и $50 \%-\mathrm{Fe}): a-$ поверхность свежеизготовленной ленты; $b$ - после отжига.

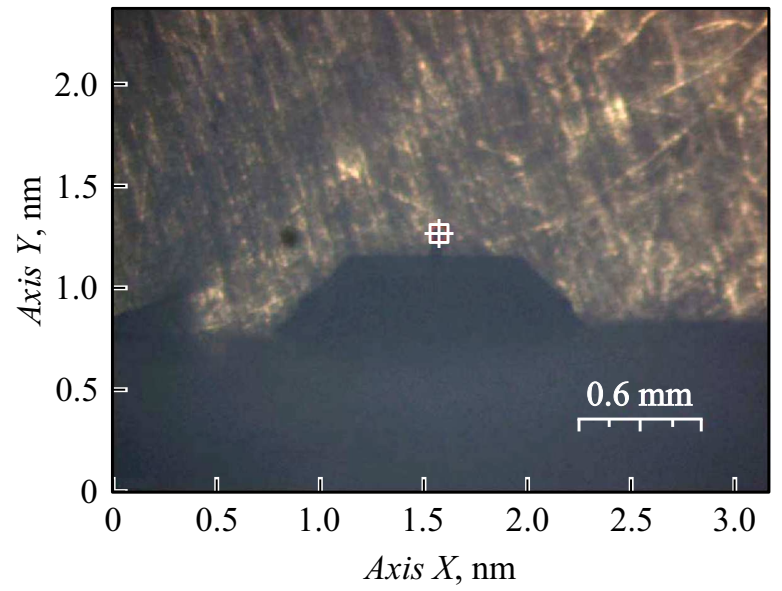

Рис. 2. SEM-изображения границы раздела сплавов $\mathrm{Co}-\mathrm{Fe}$ и $\mathrm{Ni}-\mathrm{Fe}$.

\section{Результаты измерений}

Изготовленные пленочные термопары подвергались намагничиванию в магнитном поле до значений $H=4.8 \mathrm{~A} / \mathrm{m}$. На рис. 3. представлены гистерезисные петли ленты пермаллоя $\mathrm{Co}-\mathrm{Fe}$ (нагретого до $410^{\circ} \mathrm{C}$ и закаленного в воде) в переменном и постоянном магнитном поле.

Как видно, из гистерезисной петли, намагниченность ленты достаточна для хорошего прилипания магнитомягкой гибкой термопары из сплавов $\mathrm{Co}-\mathrm{Fe}$ и $\mathrm{Ni}-\mathrm{Fe}$ к парамагнитным и ферромагнитным телам. Следует отметить, что пленки сплавов $\mathrm{Co}-\mathrm{Fe}$ и $\mathrm{Ni}-\mathrm{Fe}$ обладают высокой коэрцетивностью (20-30 Ое) [7].
Температурная зависимость дифференциальной термоЭДС $\alpha(T)$ термопары из сплавов $\mathrm{Co}-\mathrm{Fe}$ и $\mathrm{Ni}-\mathrm{Fe}$ представлена на рис. 4. В контакте сплавов положи-

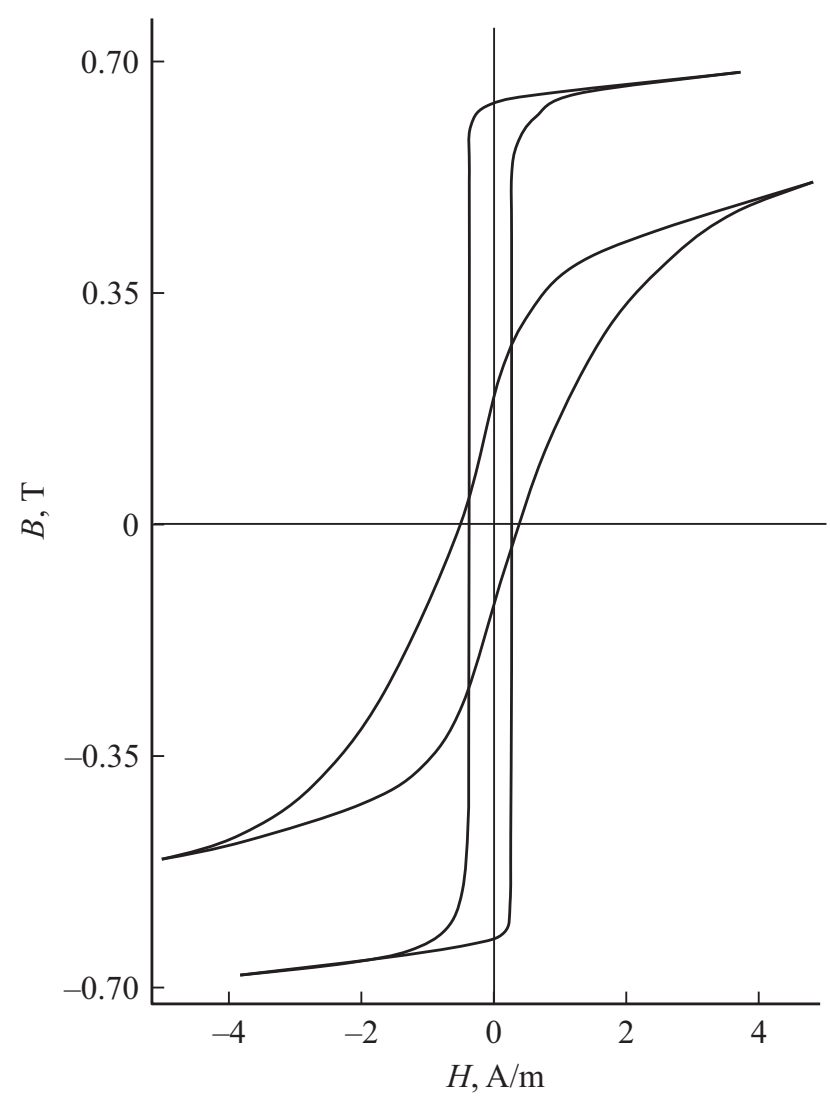

Рис. 3. Гистерезисная петля ленты пермаллоя $\mathrm{Co}-\mathrm{Fe}$, нагретого до $410^{\circ} \mathrm{C}$ и закаленного в воде: $1-$ в постоянном, $2-$ в переменном магнитном поле. 


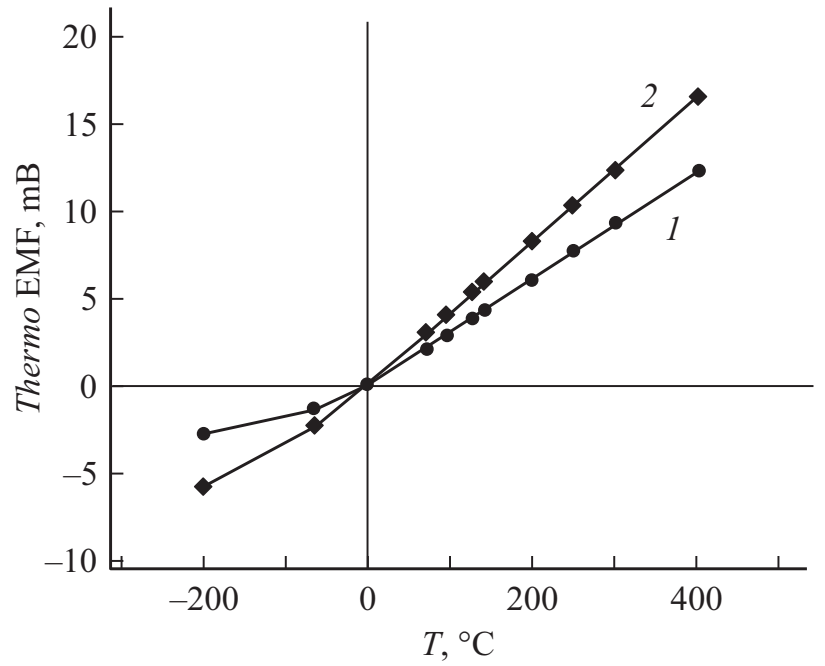

Рис. 4. Температурная зависимость дифференциальной термоЭДС термопары пермаллоев (кривая 1) и термопары хромель-алюмель (кривая 2).

тельным потенциалом обладает сплав Co-Fe. По шкале Полинга электроотрицательность железа, кобальта и никеля равны 1.83, 1.88 и 1.91 соответственно. Следовательно, контактная разность потенциалов на границе раздела формируется диффузионным потоком электронов из $\mathrm{Co}-\mathrm{Fe}$ в $\mathrm{Ni}-\mathrm{Fe}$. Ход зависимости $\alpha(T)$ термопары пермаллоев (ТП) (кривая 1) имеет одинаковый характер с аналогичной характеристикой термопары хромель-алюмель (ТХА - типа $K$ ).

Чувствительность термопары пермаллоев немного уступает чувствительности ТХА. Однако термопары пермаллоев обладают рядом преимуществ над ТХА. В частности, намагниченность ТП позволяет примкнуть к исследуемому парамагнитному или ферримагнитному объекту непосредственно за счет магнитного взаимодействия.

При воздействии переменного электромагнитного поля на проводник возникают вихри, вызывающие нагрев [3]. В случае измерения температуры проволочной термопарой TXА в зависящем от времени магнитном поле возникают погрешности в измерениях температуры, вызываемые нагревом за счет индукционных токов. Подобные погрешности с использованием термопары магнитомягких пленок пермаллоев сводятся к минимуму. Следует отметить, что в диапазоне индукции магнитного поля $0 \ldots 1.2 \mathrm{~T}$ в пределах точности измерения нашей установки $(1 \mu \mathrm{V} / \mathrm{K}, \pm 0.2 \mathrm{~K})$, какие-либо зависимости термоЭДС от магнитной проницаемости материалов термопары не выявлены.

\section{Заключение}

Магнитомягкие гибкие ленты из пермаллоев $\mathrm{Co}-\mathrm{Fe}$ и $\mathrm{Ni}-\mathrm{Fe}$ являются подходящим материалом для изготовления термоэлектрических сенсоров. Термопары, изготовленные из намагниченных тонких полосок сплавов $\mathrm{Co}-\mathrm{Fe}$ и $\mathrm{Ni}-\mathrm{Fe}$, позволяют примкнуть к исследуемому парамагнитному или ферримагнитному объекту непосредственно, за счет магнитного взаимодействия. Тонкопленочная форма ветвей термопары в переменном магнитном поле позволяет минимизировать погрешности в измерениях температуры, вызываемые нагревом за счет индукционных токов.

\section{Конфликт интересов}

Авторы заявляют, что у них нет конфликта интересов.

\section{Список литературы}

[1] Farhad Shir, Catherine Mavriplis, Lawrence H. Bennett. // Journ. Instrument. Sci. Technol. 2007. Vol. 33. P. 661-671.

[2] Kollie T.G., Anderson R.L., Horton J.L., Roberts M.J. // Rev. Scient. Instrument. 2008. Vol. 48. P. 501. https://doi.org/10.1063/1.1135063

[3] Samo Begus, Jovan Bojkovski, Janko Drnovsek, Gregor Gersa. // Measurement Sci. Technol. 2014. Vol. 25. N 3. DOI: $10.1088 / 0957-0233 / 25 / 3 / 035006$

[4] Gregor Gersak Gand, Samo Begus. // J. Thermophys. 2010. Vol. 311. P. 622-632.

[5] Биронт В.С., Дроздова Т.Н., Блохина И.В., Лындина Е.Н., Якимов И.С., Пономарева С.В., Гусев А.О., Симаков Д.А. // J. Siberian Federal University. Engineer. Technol. 2009. P. $139-150$.

[6] Козлов А.Г., Лухвич А.А., Шарандо В.Т. В кн. Физические методы и средства неразрушающего контроля. М.: Наука и техника, 1976. С. 169-171.

[7] Xiaomin Liu, Evans P., Zangari G. // IEEE Transactions on Magnetics. 2000. Vol. 36. N 5. P. 3479-3481. 